\title{
Urgent action on HPV vaccine needed to protect boys
}

Health leaders have made a joint plea in Northern Ireland for the government to take action to ensure the human papillomavirus (HPV) vaccine is introduced for boys.

The plea was made on 7 November 2018 at the annual Cancer Focus Northern Ireland (NI) Men's Health Conference held in Antrim.

The common sexually transmitted infection HPV can cause a range of cancers (cervical, vaginal, vulvar, penile, anal, and oral) as well as genital warts.

There has already been a vaccination programme for 12- to 13-year-old girls in Northern Ireland since 2008, but in July of this year, the Joint Committee on Vaccination and Immunisation recommended that boys should also receive this vaccine to ensure both sexes were protected against the cancers and other diseases caused by HPV.

Cancer Focus NI has already urged the Department of Health at Stormont to provide clarity on whether or not funding will be made available to ensure boys will benefit from the vaccine along with those in the rest of the UK.

Unless an implementation plan for the vaccine's roll out was made available soon there was a danger that boys in Northern Ireland would be left at risk, speakers at the conference warned.

Health professionals from all over Northern Ireland attended the conference, which focused on the theme of inequality for men and boys.

Guest speaker Dr Gillian Prue, from Queen's University Belfast (QUB), said she was concerned that no announcement had been made as to whether local boys would receive the HPV vaccine.

'By the end of July, it was confirmed that boys in England, Scotland and Wales would be vaccinated and work on implementation is now underway in those regions,' said
Prue. 'It is expected that these boys will start to be vaccinated from September next year. We are also expecting confirmation that Ireland will decide to vaccinate boys in the near future.'

Dr Gerry McKenna, Chair of the BDA Northern Ireland, said: 'We've seen a rise in the number of mouth and throat cancer cases in recent years and the number of cases looks set to double by 2035. Major risk factors of mouth cancer are tobacco use and drinking alcohol and a number are related to HPV exposure - cases which would be easily prevented by the introduction of this important vaccine to boys.'

Gerry McElwee, Head of Cancer Prevention for Cancer Focus NI, said: 'The Department should consider using new powers recently legislated for at Westminster to ensure local boys are not disadvantaged, as it is a decision that sits squarely in the public interest.'

\section{Health secretary's 'prevention drive' plan underwhelms}

Plans by the Health and Social Care Secretary Matt Hancock to create a NHS that focuses on prevention of ill health have been met with little enthusiasm by dentist and other health leaders.

Hancock made a speech on 5 November 2018 and published a policy paper ${ }^{1}$ in which he set out his plans to put prevention at the heart of the nation's health with a mission to improve healthy life expectancy so that, by 2035, people would enjoy at least five extra years of healthy, independent life, whilst closing the gap between the richest and poorest.

The document says primary care meaning general practice, community pharmacy, dental, and optometry services - was a central part of the health secretary's vision, and refers briefly to improving oral health of children.

It says: 'Improving dental health in children, which remains a problem in some communities. Tooth extraction is a significant and unnecessary burden on children.'

However, the BDA was unimpressed, saying the document failed to meaningfully engage on wholly preventable oral diseases like tooth decay.
The trade union said tooth decay was the number one reason for hospital admissions for children aged 5-9, and paediatric extractions have cost the NHS $£ 165$ million on extractions in hospitals since 2012 - but neither of these facts had been acknowledged or addressed in the government paper.

In addition, deep and preventable oral health inequalities persisted in both child and adult populations, said the BDA, pointing out that in the last five years, the Government's spend per head on NHS dentistry had fallen from $£ 40.95$ to $£ 36$, while patient charges had increased by over $23 \%$.

A BDA spokesperson said: 'The Government's centrepiece Starting Well oral health programme, which is targeting high needs children, has not received a penny of new investment, and is operating in parts of just 13 local authorities in England.'

BDA Chair Mick Armstrong said: 'The Health Secretary says he wants to champion prevention. Sadly he's had more to say about broccoli than wholly preventable oral diseases that are costing our NHS millions.

'When tooth decay remains the number one reason for child hospital admissions, treating dentistry as an afterthought looks more than careless. England's huge oral health inequalities are fuelled by poverty and the lack of a coherent strategy.

'The starting point for any solution won't be "Big Data" or Apps, it requires political will from Westminster and an end to year on year cuts.'

The British Medical Association (BMA) welcomed the intention of the paper, but questioned how it would be achieved, calling for public health prevention to be a priority.

BMA public health committee chair, Dr Peter English, said: 'While the plans outlined in this paper are a welcome step, the government must be realistic about what must be required in order to deliver this.

'There is a need to reverse the cuts to public health budgets, as in many areas, public health services do not adequately meet the health needs of the local population. Reductions to services such as smoking cessation and sexual health in some areas are directly contributing to unacceptable variations in the quality and quantity of care available to the population. 
4 Niall Dickson, Chief Executive of the NHS Confederation, which represents organisations across the healthcare sector, said: 'Preventing illness and disease is huge area with enormous potential - much of it extending well beyond the NHS.

'We need to support interventions that have been shown to work - from drugs that prevent strokes and heart disease, to tackling obesity among children.

'Of course, we have been here before and the recent record of cutting public health spending must now be reversed.'

1. Department of Health and Social Care. Prevention is better than cure: Our vision to help you live well for longer (5 November 2018). Available at https:// www.gov.uk/government/publications/prevention-is better-than-cure-our-vision-to-help-you-live-well-forlonger. (accessed on 5 November 2018).

\section{Budget will mean less spending on workforce training}

Less money will be spent training the NHS workforce including dentists, doctors and nurses, it has been claimed, following the recent Budget delivered on 29 October 2018 by Chancellor Philip Hammond.

In his Budget, Hammond confirmed the announcement made earlier this year that the NHS would receive a $£ 20.5$ billion increase in funding over the next five years.

Following the speech, think tank the Health Foundation produced an analysis that said the NHS England resource budget would increase by $£ 5.1$ billion in real terms next year (including $£ 1.25$ billion to cover additional pension costs.

The Department of Health and Social Care (DHSC) resource budget (which includes NHS England as well as wider health spending) was only increasing by $£ 4$ billion, therefore wider health spending would see a $£ 1$ billion reduction next year, unless the $£ 1.25$ billion was added to the published DHSC resource budget.

The impact of this would mean cuts to spending across public health, workforce training and capital investment in buildings and equipment, said the Health Foundation.

Professor Anita Charlesworth, Director of Research and Economics for the Health Foundation, said: 'The NHS was the clear winner in the Chancellor's budget but there is a risk that it won't feel like that in hospitals and GP surgeries over the coming year. Extra funding starts next year and rises to $£ 20.5$ billion in 2023-24. The money is not for front-line NHS services.

'It excludes wider areas of vital health spending where funding is also desperately needed; public health, workforce training and capital investment.'

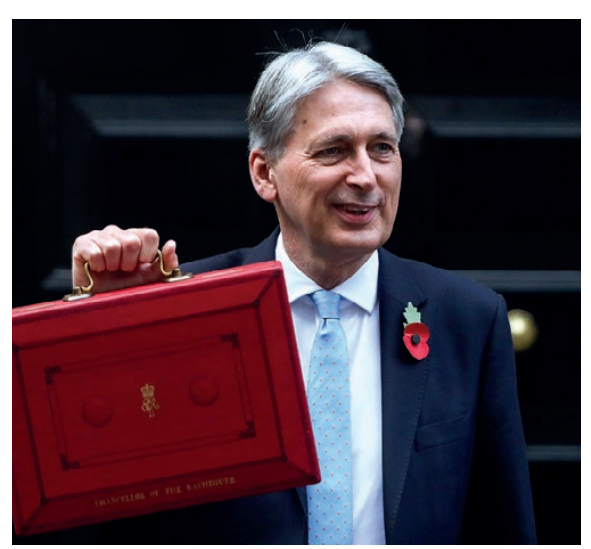

Chancellor of the Exchequer, Philip Hammond

Other announcements made in the Budget included:

- From the next financial year, the amount you can earn before paying tax will rise from $£ 11,850$ to $£ 12,500$, and the threshold for the higher rate of tax will increase from $£ 46,350$ to $£ 50,000$

- The government reformed the off-payroll working rules for the public sector in April 2017. The latest budget announced an extension of these reforms to the private sector too, to ensure individuals who effectively work as employees are taxed as employees, even if they are technically self-employed. Small companies and organisations will be exempt, and the Treasury will provide detailed guidance to medium and large organisations ahead of implementation in April 2020

- From April 2019, the National Living Wage will increase from $£ 7.83$ to $£ 8.21$

- Business rates will be cut by a third for retail properties with a rateable value below $£ 51,000$ for 2 years from April 2019

- Business rates will be revaluated from 2021. 